\title{
The prevalence and expression pattern of melanoma-associated antigen 1 in esophageal squamous cell carcinoma: a historical cohort study
}

Kazem Anvari ${ }^{1}$, Azar Fani Pakdel ${ }^{2}$, Bahram Memar ${ }^{3}$, Roya Parsamanesh ${ }^{4}$, Seyyed Mojtaba Ejlalzadeh ${ }^{4}$, Seyed Alireza Javadinia ${ }^{5}$

${ }^{1}$ M.D., Associate Professor, Cancer Research Center, Mashhad University of Medical Sciences, Mashhad, Iran

${ }^{2}$ M.D., Assistant Professor, Cancer Research Center, Mashhad University of Medical Sciences, Mashhad, Iran

${ }^{3}$ M.D., Assistant Professor, Department of Pathology, Mashhad University of Medical Sciences, Mashhad, Iran

${ }^{4}$ M.D., Faculty of Medicine, Islamic Azad University, Mashhad, Iran

${ }^{5}$ M.D., Student Research Committee, Department of Radiation Oncology, Faculty of Medicine, Mashhad University of Medical Sciences, Mashhad, Iran

\section{Type of article: Original}

\begin{abstract}
Introduction: Melanoma-associated antigen 1 (MAGE1) expression in normal tissues is restricted to the testes, whilst being over-expressed in a number of human cancers. This feature of MAGE1 makes it a promising cancer biomarker. This study aimed to determine the expression of MAGE1 in esophageal squamous cell carcinoma (SCC) and its relationship with clinicopathological factors.

Methods: This is a cross-sectional study conducted on pretreatment endoscopic tissue specimens of 43 patients with non-metastatic esophageal SCC, admitted to Omid Hospital, Mashhad, Iran, between 2011 and 2013 . Out of 127 esophageal SCC patients who had already enrolled in a trial of trimodality therapy, we chose 43 patients whose paraffin blocks of endoscopic samples were accessible, which we then stained for MAGE1 expression by immunohistochemistry. Correlation of MAGE1expression and clinicopathological data (age, sex, stage, grade, and outcome) was assessed using SPSS 16 by T test, chi-square, and Pearson tests ( $\mathrm{p}<0.05$ was considered significant).

Results: MAGE1 was expressed in 46.5\% (20 out of 43) of esophageal SCC specimens. The MAGE1 nuclear staining increased significantly by age; its expression for $<40,41-49,50-59,60-69$, and $\geq 70$ years old was $0 \%$, $0 \%, 8.3 \%, 26.3 \%$, and $100 \%$, respectively ( $\mathrm{p}=0.02$; Person's $\mathrm{R}$ value $=0.3$ and $\mathrm{p}=0.04$ ). There was no significant correlation between MAGE1 expression and other clinicopathological parameters.

Conclusion: MAGE1 antigen has considerable expression in the esophageal SCC among the Iranian population; it can be potentially applied as a cancer biomarker as well as a target for immunotherapy in patients with esophageal SCC.

Keywords: Cancer Testis Antigen, Melanoma-associated antigen 1, Esophageal cancer, Squamous cell carcinoma
\end{abstract}

\section{Introduction}

The esophageal cancer is an extremely lethal disease worldwide; however, the prognosis of esophagus cancer in Iran is not as dismal as in other regions of the world (1-3). Although the prevalence of this neoplasm is relatively low globally, it is one of the most prevalent in Iran (4), ranking fifth and eighth among all types of cancers in women and men, respectively. Its incidence, however, varies according to its geographic distribution; i.e. it is more prevalent in the northern regions of Iran; Khorasan Razavi stands at third place for men and fourth place for women (5). Furthermore, Mashhad University of Medical Sciences is a referral center for cancer patients from adjacent

\section{Corresponding author:}

Assistant Professor Dr. Azar Fani Pakdel, Department of Radiation Oncology, Faculty of Medicine, Mashhad University of Medical Sciences, Mashhad, Iran.

Tel: +98.5138426936, Email: Fanipa@mums.ac.ir and fanipakdela@gmail.com

Received: October 08, 2016, Accepted: January 20, 2017, Published: February 2017

iThenticate screening: November 29, 2016, English editing: February 01, 2017, Quality control: February 06, 2017

(C) 2017 The Authors. This is an open access article under the terms of the Creative Commons Attribution-NonCommercialNoDerivs License, which permits use and distribution in any medium, provided the original work is properly cited, the use is non-commercial and no modifications or adaptations are made. 
provinces, namely Golestan, North Khorasan, etc. Currently, there is no definitive and efficient recommended standard for treatment of esophageal cancer, due to paucity of appropriately designed studies (6). Esophageal squamous cell carcinoma (SCC) is preceded by squamous dysplasia as a result of genetic divergence manifested by canonical oncogenes and tumor suppressor genes in somatic cells of the tumor. This genetic divergence consists of oncogenes such as epidermal growth factor receptor (EGFR) and cyclin D, and tumor suppressor genes such as P16INK4a and TP53 (7). Novel realizations of underlying molecular pathogenesis and biology of esophageal cancer have led to a resurgent interest in the study of targeted therapy in the field of this neoplasm (8). Early reports on adding vascular endothelial growth factor (VEGF) ligand-targeted agent and EGFR- targeted agent to chemoradiation, showed no improved outcomes. Therefore, currently available EGFR targeted therapies are not in use for esophageal cancers (9). However, ramucirumab, a human monoclonal antibody against VEGF2, has shown positive results in refractory esophageal cancer (10). To date, human epidermal growth factor receptor 2 (HER 2) targeted agent, trastuzumab, is the only targeted agent approved for treatment of metastatic HER 2 positive esophagogastric adenocarcinoma (9). Among different therapeutic targets identified, tumor specific antigens (TSAs) and tumor associated antigens (TAAs) are unique because of their exclusive expression in malignant tissues (disregarding testis) (11). CTAs, a group of TSAs/TAAs consisting of more than 100 immunogenic proteins including melanoma-associated antigen (MAGE), BAGE and GAGE families among others, are characterized by an unusual expression profile, mostly limited to the pre-meiotic germ cells of adult testis and cancer cells of diverse histological origin such as melanoma and carcinoma of breast and gastrointestinal tract $(12,13)$. MAGE1 expression in normal tissue is restricted to the testes, whilst being over-expressed in a number of human cancers. The MAGE family which is located on X-chromosome is frequently expressed in different carcinomas, and has diagnostic and therapeutic potentials. For example, MAGE is correlated with SCC histology in lung cancers $(14,15)$, with hormone-receptor-negative carcinomas in breast cancers (16), and with high-grade carcinomas in urothelial neoplasms (17). Several investigators proposed that MAGE1 plays a potential role in the carcinoma of the digestive tract, especially for the esophageal carcinoma. Haier et al reported that MAGE1 was expressed in half of esophageal SCCs; however, they did not find any prognostic value in this context (18). Chen et al and Liang et al showed that this antigen was expressed frequently in SCC of esophagus and was related to tumor progression $(19,20)$. These controversies still remain unresolved: whether MAGE1 cancer testis antigen has a specific clinicopathologic importance in high incidence areas such as Iran, has yet to be proved. In this study, we aimed to determine the expression of MAGE1 in Esophageal Squamous Cell Carcinoma and its relationship with clinicopathological factors in the north-east of Iran.

\section{Material and Methods}

\subsection{Patients and Treatment}

This was a cross-sectional study conducted on pretreatment endoscopic tissue specimens of 43 patients with nonmetastatic esophageal SCC, admitted to Omid Hospital, Mashhad University of Medical Sciences, Mashhad, Iran, between 2011 and 2013. They had all undergone neoadjuvant chemoradiation (CRT) in a prospective clinical phase II trial, described by Anvari et al (2). In their study, 197 patients with stage Ib-IIIc esophageal SCC were recruited, 127 patients completed treatment, fourteen patients died due to surgical complications and two patients died of other causes. Of the 111 patients remaining, we had access to 43 patients' paraffin blocks of endoscopic SCC samples with detectable tumoral cells which were used in our study. CRT consisted of 40 gray radiotherapy and two courses of concurrent chemotherapy with cisplatin $20 \mathrm{mg} / \mathrm{m} 2$ for 4 days, plus 5 -FU $700 \mathrm{mg} / \mathrm{m} 224$-h continuous infusion for 4 days in the 1st and 4th weeks of radiation therapy. Esophagectomy was performed 3-4 weeks after radiation therapy termination using the transhiatal technique with regional lymph node dissection. The mean number of resected lymph nodes was $4.05 \pm 2.79(0-11)$.

\subsection{Immunohistochemistry (IHC) and Scoring}

Immunohistochemical staining of MAGE1 was performed on pretreatment endoscopic specimens (before neoadjuvant CRT). For the detection of MAGE1 antigen, we used diluted NCL-MAGE1 monoclonal antibody $(\mathrm{mAb})$, with the staining method described in detail below, according to Bolli's study (21). Tissue slides from paraffin embedded esophageal SCC samples were placed on Silane (3 aminopropyltriethoxysilane, A 3648, Sigma, St. Louis MO, USA). The deparaffinized slides were heated in an 800-W microwave oven at maximum power for 30 minutes (min), soaked in $10 \mathrm{mmol} / \mathrm{l}$ EDTA buffer ( $\mathrm{pH} \mathrm{6.0)}$ ) for $5 \mathrm{~min}$ and then rinsed with a tris buffer solution (PBS, pH 7.2). The tris buffer solution was composed of saline, surfactant, and protein stabilizer $0.35 \%$ ProClinTM 950. To suppress endogenous peroxidase activity, slides were treated with $\mathrm{H} 2 \mathrm{O} 2$. After additional rinsing with PBS, they were incubated for $20 \mathrm{~min}$ with a 1:10 dilution of normal rabbit serum (DakoX0902, Dako A/S) in a wet chamber at room temperature for 20 min to prevent non-specific binding of immunoglobulin. Dilutions were made 
of 1:50 and 1:100 of NCL-MAGE1 mAb with $1 \mathrm{cc}$ of sterile distilled water. Slides were then treated with diluted mAbs at room temperature for $90 \mathrm{~min}$. The Envision (Dako) system was used as a secondary detection tool and diaminobenzidine tetrahydrochloride served as a chromogen. The slides were counterstained with hematoxylin prior to our evaluation. Sections of normal human testis with intact spermiogenesis were used as positive controls for MAGE1 mAbs. Each dilution was performed on the same type of sample in order to retain the exact experimental conditions. Figure 1 shows IHC staining for MAGE1 in tumoral cells. MAGE1 staining results were scored according to Allred scoring system (22), consisting of four categories based on microscopic observations including strongly positive, moderately positive, weakly positive and no staining. All results of IHC were reported based on the mutual assessment of two expert pathologists. We graded pathologic response on a 0-3 scale as follows; complete response (Grade 0) as no cancer cells, moderate response (Grade 1) as single cells or small groups of cancer cells, minimal response (Grade 2) as residual cancer cells outgrowth by fibrosis, and poor response (Grade 3) as minimal or no treatment effect. Then they were categorized into two general subgroups: favorable response (grade 0 and 1 ) and unfavorable response (grade 2 and 3 ).
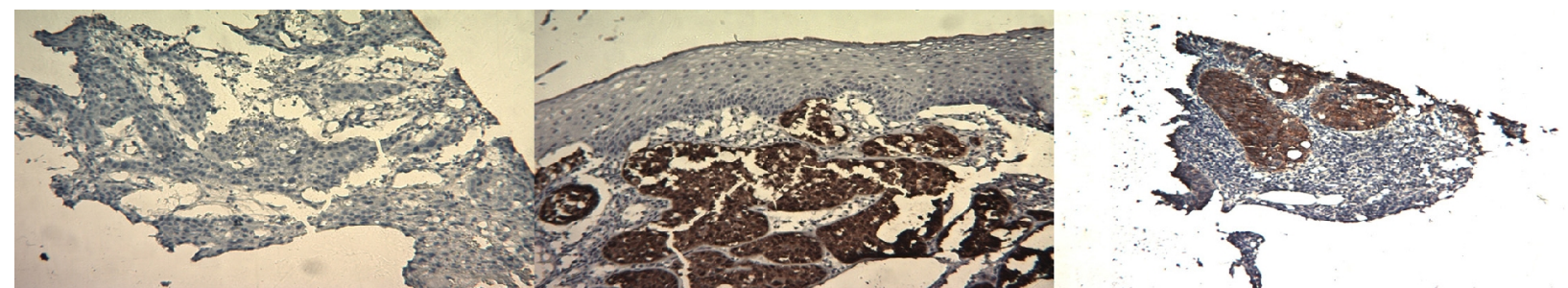

Figure 1. IHC staining for MAGE1; left: tumoral cells are completely negative for MAGE1 (IHC study by monoclonal anti-MAGE1, $\left.{ }^{*} 100\right)$ middle: strong and diffuse nuclear and cytoplasmic staining for MAGE1 in tumoral cells (center and lower half) and negative in normal squamous epithelium (upper third) $(* 100)$ right: strong and diffuse staining for MAGE1 in cytoplasm of tumoral cells, but negative in nuclei of tumoral cells $(* 100)$

\subsection{Statistical Analysis}

The sample size used in the study ( $\mathrm{n}=43$ ) was determined based on Haier et al. (18) using $\mathrm{n}=\mathrm{Z} 21-\alpha / 2 \mathrm{P}(1-\mathrm{P}) / \mathrm{d} 2$ while the confidence interval, estimated proportion, and desired precision was considered $90 \%, 50 \%$, and $\mathrm{d} / 4$, respectively. The association between immunohistochemical findings and different clinicopathological parameters was evaluated by chi-square test, T-test, and Pearson test; $p<0.05$ was considered significant. For all statistical analyses, the computer program SPSS 16 (SPSS Inc. Chicago, Illinois, USA) was used.

\subsection{Research Ethics}

This study was approved by the Ethics Committee of Mashhad University of Medical Sciences after its scientific approval by the Department of Radiation Oncology (reference number for main clinical trial: MUMS/931296; reference number for this study: MUMS/930840). The ethical rules of research according to Helsinki Declaration were observed. Also, we were committed to keeping all of the participants' information confidential.

\section{Results}

Tissue specimens of 43 patients with non-metastatic esophageal squamous cell carcinoma were selected. Patients' demographic information and tumor TNM status are summarized in Table1. The median follow-up time was 32 months (range: 32-83), of which in 18 (43.9\%) death occurred, while the median disease free survival time was 27 months (95\% CI: 21.11-34.56).

\subsection{MAGE1 cytoplasmic and nuclear expression}

MAGE1 was expressed in 46.5\% (20 out of 43) of esophageal SCC specimens, overall. MAGE1 cytoplasmic and nuclear expression was detected in $34.9 \%$ (15 out of 43 ) and $30.2 \%$ (13 out of 43 ) of specimens, respectively (Figure 2).

\subsection{Association between MAGE1 cytoplasmic/nuclear expression and different clinicopathological parameters}

MAGE1 nuclear staining increased significantly by age (Person's $R$ value $=0.3$ and $p=0.04$ ). There was no significant correlation between MAGE1 cytoplasmic/nuclear expression and gender, tumor stage, lymph node status, tumor grade, disease free survival, outcome, and pathologic complete response (pCR). Associations between MAGE1 expression and clinicopathological variables are presented in Tables 2 and 3. 
Table 1. Demographic and TNM status of patients.

\begin{tabular}{|l|l|l|}
\hline Variable & Female & n (\%) \\
\hline \multirow{3}{*}{ Gender } & Male & $21(48.8)$ \\
\hline \multirow{5}{*}{ T stage (years) } & $<54$ & $22(51.2)$ \\
\cline { 2 - 3 } & $55-64$ & $18(41.9)$ \\
\cline { 2 - 3 } & $>65$ & $11(25.6)$ \\
\hline \multirow{5}{*}{ N stage } & Carcinoma in situ & $14(23.6)$ \\
\cline { 2 - 3 } & T1 & $4(9.3)$ \\
\cline { 2 - 3 } & T2 & $12(27.9)$ \\
\cline { 2 - 3 } & T3 & $17(39.5)$ \\
\hline M stage & N0 & $34(79.1)$ \\
\cline { 2 - 3 } & N positive & $7(16.3)$ \\
\cline { 2 - 3 } & N/E & $2(4.7)$ \\
\hline Grade & M0 & $43(100)$ \\
\cline { 2 - 3 } & M1 & $14(32.6)$ \\
\hline Pathologic response & 1 & $12(27.9)$ \\
\cline { 2 - 3 } & 2 & $25(58.1)$ \\
\cline { 2 - 3 } & Unfavorable & $18(41.9)$ \\
\cline { 2 - 3 } & Favorable & \\
\hline
\end{tabular}

Table 2. Association between MAGE1 cytoplasmic expression and different clinicopathological parameters.

\begin{tabular}{|c|c|c|c|c|c|c|c|}
\hline \multicolumn{3}{|c|}{ Clinicopathological Parameter } & \multicolumn{5}{|c|}{ Cytoplasmic expression; n (\%) } \\
\hline \multicolumn{2}{|l|}{ Variables } & $\mathrm{n}$ & Negative & Weakly Positive & Moderately Positive & Strongly Positive & p-value \\
\hline \multirow[t]{2}{*}{ Gender } & Male & 22 & $13(59.1 \%)$ & $2(9.1 \%)$ & $2(9.1 \%)$ & $5(22.7 \%)$ & \multirow[t]{2}{*}{0.2} \\
\hline & Female & 21 & $15(71.4 \%)$ & $3(14.3 \%)$ & $2(9.5 \%)$ & $1(4.8 \%)$ & \\
\hline \multirow[t]{3}{*}{ Age (years) } & $<54$ & 18 & $13(72.2 \%)$ & $2(11.1 \%)$ & $0(0 \%)$ & $3(16.7 \%)$ & \multirow[t]{3}{*}{0.7} \\
\hline & $55-64$ & 11 & $6(54.5 \%)$ & $1(9.1 \%)$ & $3(27.3 \%)$ & $1(9.1 \%)$ & \\
\hline & $>65$ & 14 & $9(64.3 \%)$ & $2(14.3 \%)$ & $1(7.1 \%)$ & $2(14.3 \%)$ & \\
\hline \multirow[t]{4}{*}{ Tumor stage } & $\mathrm{T}$ in & 10 & $7(70 \%)$ & $1(10 \%)$ & $1(10 \%)$ & $1(10 \%)$ & \multirow[t]{4}{*}{0.1} \\
\hline & $\mathrm{T} 1$ & 4 & $4(100 \%)$ & $0(0 \%)$ & $0(0 \%)$ & $0(0 \%)$ & \\
\hline & $\mathrm{T} 2$ & 12 & $9(75 \%)$ & $1(8.40 \%)$ & $2(16.6 \%)$ & $0(0 \%)$ & \\
\hline & T3 & 17 & $8(47 \%)$ & $3(17.6 \%)$ & $1(6 \%)$ & $5(29.4 \%)$ & \\
\hline \multirow{3}{*}{$\begin{array}{l}\text { Lymph node } \\
\text { status }\end{array}$} & N0 & 34 & $23(67.6 \%)$ & $3(8.8 \%)$ & $3(8.8 \%)$ & $5(14.8 \%)$ & \multirow[t]{3}{*}{0.8} \\
\hline & $\mathrm{N}$ positive & 7 & $4(57.2 \%)$ & $2(28.6 \%)$ & $0(0 \%)$ & $1(14.2 \%)$ & \\
\hline & $\mathrm{N} / \mathrm{E}$ & 2 & $1(50 \%)$ & $0(0 \%)$ & $1(50 \%)$ & $0(0 \%)$ & \\
\hline \multirow[t]{3}{*}{ Tumor grade } & I & 14 & $11(78.7 \%)$ & $1(7.1 \%)$ & $1(7.1 \%)$ & $1(7.1 \%)$ & \multirow[t]{3}{*}{0.1} \\
\hline & II & 12 & $9(75 \%)$ & $1(8.3 \%)$ & $2(16.7 \%)$ & $0(0 \%)$ & \\
\hline & III & 17 & $8(50 \%)$ & $3(0 \%)$ & $1(0 \%)$ & $5(50 \%)$ & \\
\hline \multirow[t]{2}{*}{$\overline{P C R}$} & Unfavorable & 18 & $9(50 \%)$ & $4(22.2 \%)$ & $1(5.6 \%)$ & $4(22.2 \%)$ & \multirow[t]{2}{*}{0.1} \\
\hline & Favorable & 25 & $19(76 \%)$ & $1(4 \%)$ & $3(12 \%)$ & $2(8 \%)$ & \\
\hline \multirow{3}{*}{$\begin{array}{l}\text { Disease free } \\
\text { survival } \\
\text { (month) }\end{array}$} & $<12$ & 13 & $9(69.2 \%)$ & $1(7.7 \%)$ & $0(0 \%)$ & $3(23.1 \%)$ & \multirow[t]{3}{*}{0.4} \\
\hline & $12-24$ & 9 & $7(77.8 \%)$ & $2(22.2 \%)$ & $0(0 \%)$ & $0(0 \%)$ & \\
\hline & $>24$ & 18 & $10(55.6 \%)$ & $2(11.1 \%)$ & $4(22.2 \%)$ & $2(11.1 \%)$ & \\
\hline \multirow[t]{2}{*}{ Outcome } & Death & 18 & $12(66.7 \%)$ & $3(16.7 \%)$ & $1(5.6 \%)$ & $2(11.1 \%)$ & \multirow[t]{2}{*}{0.8} \\
\hline & Alive & 23 & $15(65.2 \%)$ & $2(8.7 \%)$ & $3(13 \%)$ & $3(13 \%)$ & \\
\hline
\end{tabular}


http://www.ephysician.ir

Table 3. Association between MAGE1 nuclear expression and different clinicopathological parameters.

\begin{tabular}{|c|c|c|c|c|c|c|c|}
\hline \multicolumn{3}{|c|}{ Clinicopathological Parameter } & \multicolumn{5}{|c|}{ Nuclear expression; $\mathrm{n}(\%)$} \\
\hline \multicolumn{2}{|c|}{ Variables } & $\mathrm{n}$ & Negative & Weakly Positive & Moderately Positive & Strongly Positive & p-value \\
\hline \multirow[t]{2}{*}{ Gender } & Male & 22 & $16(72.7 \%)$ & $1(4.5 \%)$ & $1(4.5 \%)$ & $4(18.2 \%)$ & \multirow[t]{2}{*}{0.7} \\
\hline & Female & 21 & $14(66.7 \%)$ & $3(14.3 \%)$ & $0(0 \%)$ & $4(19 \%)$ & \\
\hline \multirow[t]{3}{*}{ Age (years) } & $<54$ & 18 & $16(88.9 \%)$ & $1(5.6 \%)$ & $0(0 \%)$ & $1(5.6 \%)$ & \multirow[t]{3}{*}{$0.04 *$} \\
\hline & $55-64$ & 11 & $6(54.5 \%)$ & $2(18.2 \%)$ & $0(0 \%)$ & $3(27.3 \%)$ & \\
\hline & $>65$ & 14 & $8(57.1 \%)$ & $1(7.1 \%)$ & $1(7.1 \%)$ & $4(28.6 \%)$ & \\
\hline \multirow[t]{4}{*}{ Tumor stage } & $\mathrm{T}$ in & 10 & $7(70 \%)$ & $1(10 \%)$ & $1(10 \%)$ & $1(10 \%)$ & \multirow[t]{4}{*}{0.2} \\
\hline & $\mathrm{T} 1$ & 4 & $3(75 \%)$ & $1(25 \%)$ & $0(0 \%)$ & $0(0 \%)$ & \\
\hline & $\mathrm{T} 2$ & 12 & $8(66.6 \%)$ & $2(16.7 \%)$ & $0(0 \%)$ & $2(16.7 \%)$ & \\
\hline & T3 & 17 & $12(70 \%)$ & $0(0 \%)$ & $0(0 \%)$ & $5(30 \%)$ & \\
\hline \multirow{3}{*}{$\begin{array}{l}\text { Lymph node } \\
\text { status }\end{array}$} & N0 & 34 & $23(67.7 \%)$ & $4(11.7 \%)$ & $1(2.9 \%)$ & $6(17.7 \%)$ & \multirow[t]{3}{*}{0.5} \\
\hline & N positive & 7 & $6(85.8 \%)$ & $0(0 \%)$ & $0(0 \%)$ & $1(14.2 \%)$ & \\
\hline & $\mathrm{N} / \mathrm{E}$ & 2 & $1(50 \%)$ & $0(0 \%)$ & $0(0 \%)$ & $1(50 \%)$ & \\
\hline \multirow[t]{3}{*}{ Tumor grade } & I & 14 & $10(71.4 \%)$ & $2(14.2 \%)$ & $1(7.2 \%)$ & $1(7.2 \%)$ & \multirow[t]{3}{*}{0.1} \\
\hline & II & 12 & $8(66.6 \%)$ & $2(16.7 \%)$ & $0(0 \%)$ & $2(16.7 \%)$ & \\
\hline & III & 17 & $12(70.6 \%)$ & $0(0 \%)$ & $0(0 \%)$ & $5(29.4 \%)$ & \\
\hline \multirow[t]{2}{*}{$\mathrm{pCR}$} & Unfavorable & 18 & $13(72.2 \%)$ & $0(0 \%)$ & $0(0 \%)$ & $5(27.8 \%)$ & \multirow[t]{2}{*}{0.9} \\
\hline & Favorable & 25 & $17(68 \%)$ & $4(16 \%)$ & $1(4 \%)$ & $3(12 \%)$ & \\
\hline \multirow{3}{*}{$\begin{array}{l}\text { Disease free } \\
\text { survival } \\
\text { (month) }\end{array}$} & $<12$ & 13 & $10(76.9 \%)$ & $0(0 \%)$ & $0(0 \%)$ & $3(23.1 \%)$ & \multirow[t]{3}{*}{0.6} \\
\hline & $12-24$ & 9 & $6(66.7 \%)$ & $1(11.1 \%)$ & $0(0 \%)$ & $2(22.2 \%)$ & \\
\hline & $>24$ & 18 & $11(61.1 \%)$ & $3(5.6 \%)$ & $1(22.2 \%)$ & $3(16.7 \%)$ & \\
\hline \multirow[t]{2}{*}{ Outcome } & Death & 18 & $11(61.1 \%)$ & $2(11.1 \%)$ & $1(5.6 \%)$ & $4(22.2 \%)$ & \multirow[t]{2}{*}{0.7} \\
\hline & Alive & 23 & $17(73.9 \%)$ & $2(8.7 \%)$ & $0(0 \%)$ & $4(17.4 \%)$ & \\
\hline
\end{tabular}

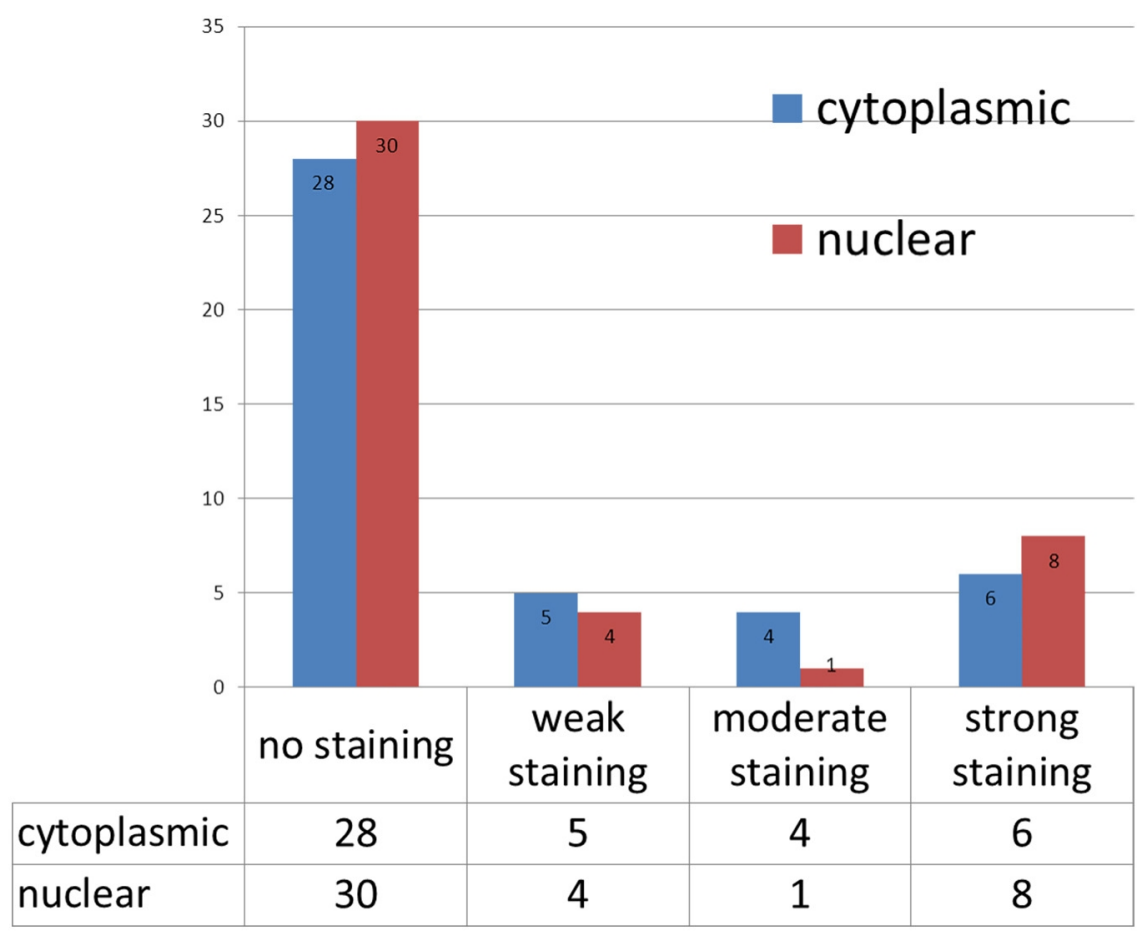

Figure 2. MAGE1 cytoplasmic and nuclear expression pattern.

\section{Discussion}

In this cross-sectional study, we determined the prevalence and pattern of MAGE1 expression in esophageal SCC and its clinicopathological significance in Iran as a high incidence area for esophageal cancers. The prevalence of cytoplasmic and nuclear MAGE1 expression was $34.9 \%$ and $30.2 \%$, respectively, with a high variability in intensity and homogeneity. There was a significant and positive correlation between MAGE1 nuclear expression and age. Cancer/testis antigens exist normally in the testis tissue; they are protected by blood-testis barrier from the immune 
system. Cancer/testis antigens in the malignant cells, and peptides derived from them, can stimulate immune response, resulting in endogenous death of tumoral cells expressing these antigens (23-25). Thus, they have two unique features; 1) their confined expression in the tumoral and testicular cells 2) their immunogenic nature. These features make them potential targets for immunotherapy, and, chemoradiotherapy-induced immunogenic cell death (26-28). Previous studies have shown a considerable prevalence of MAGE1 expression in esophageal SCC, as did our study. A 2005 study by Liang et al measured the MAGE1 gene expression via RT-PCR and reported the gene overexpression in $25.7 \%$ of esophageal SCCs (20). The prevalence of MAGE1 in studies by Haier et al in 2006 and Chen et al in 2014 was $50 \%$ and $57 \%$ respectively $(18,19)$. Immunohistochemistry technique was used in these studies, similar to ours $(18,19)$. A 2011 study by Forghanifard et al showed that MAGE1 mRNA was overexpressed in $90.2 \%$ of esophageal SCC specimens in the Iranian population (29). MAGE1 antigen has a considerable expression in the Iranian esophageal SCC patients which is independent of gender, local invasion ( $\mathrm{T}$ and N stages) and differentiation (grade). To the best of our knowledge, this study is among the first studies to determine the prevalence and pattern of MAGE1 expression in esophageal SCC and its clinicopathological significance in Iran. All together, these data demonstrate the importance of cancer/testis antigens, especially MAGE1 in esophageal SCC, and leading to its use as a potential target for immunotherapy as well as a diagnostic tool. Furthermore, immunohistochemistry, a simple and widely available method for examination of specimens, was applied. Although in other studies the correlation between age and expression of MAGE1 has been seen to be inconsistent $(18,30)$, the results of this study showed a positive association between MAGE1 expression scores and older age. Given that the esophagectomy is a high risk surgery among the elderly, leading to suboptimal treatment, or even life threatening complications (31), MAGE1 might provide a potential treatment target for these patients. Some authors have suggested that the expression of MAGE1 antigens is associated with dedifferentiation in various tumor entities (32), although neither we nor other authors found this correlation to exist $(18,30)$. Also, like previous reports, no relationship between MAGE1 expression and TNM classification was found in our study $(18,30)$.

\section{Conclusions}

The prevalence of cytoplasmic and nuclear MAGE1 expression was $34.9 \%$ and $30.2 \%$, respectively, which can be seen as considerable. Furthermore, the MAGE1 nuclear staining prevalence increased significantly by age. As a practical implication, the MAGE1 antigen could be used as a target for immunotherapy in a large proportion of esophageal SCC patients who express this antigen. In addition, high levels of MAGE1 expression in the elderly, indicate a possible and distinguished clinical benefit of immunotherapy in this subgroup of patients who may be unable to tolerate the standard treatment modalities. We also suggest further prospective studies assessing the prognostic and predictive value of the MAGE1 expression-possibly in a multicenter design, with a special focus on elderly patients.

\section{Acknowledgments:}

This research was derived from the thesis of a medical student (MD degree) of Open University; Mashhad Branch, and was supported by Mashhad University of Medical Sciences (Grant: MUMS/930840). We thank our colleagues at the Cancer Research Center, Omid Hospital, Mashhad University of Medical Sciences, especially Dr. Mitra Fazl Ersi and Ms. Ahmadi-Simab who provided insight and expertise that greatly assisted the research, although they may not agree with all of the interpretations of this paper.

\section{Conflict of Interest:}

There is no conflict of interest to be declared.

\section{Authors' contributions:}

All authors contributed to this project and article equally. All authors read and approved the final manuscript.

\section{References:}

1) Castro C, Bosetti C, Malvezzi M, Bertuccio P, Levi F, Negri E, et al. Patterns and trends in esophageal cancer mortality and incidence in Europe (1980-2011) and predictions to 2015. Ann Oncol. 2014; 25(1): 283-90. doi: 10.1093/annonc/mdt486. PMID: 24356640.

2) Anvari K, Aledavood SA, Toussi MS, Forghani MN, Mohtashami S, Rajabi MT, et al. A clinical trial of neoadjuvant concurrent chemoradiotherapy followed by resection for esophageal carcinoma. J Res Med Sci. 2015; 20(8): 751-6. doi: 10.4103/1735-1995.168377. PMID: 26664422, PMCID: PMC4652308. 
3) Salek R, Bezenjani SE, Saedi HS, Ashkiki MH, Hosainzade SM, Mohtashami S, et al. A geographic area with better outcome of esophageal carcinoma: is there an effect of ethnicity and etiologic factors? Oncology. 2009; 77(3-4): 172-7. doi: 10.1159/000231887. PMID: 19641336.

4) Nikfarjam Z, Massoudi T, Salehi M, Salehi M, Khoshroo F. Demographic survey of four thousand patients with 10 common cancers in North Eastern Iran over the past three decades. Asian Pacific journal of cancer prevention: APJCP. 2014; 15(23): 10193-8. PMID: 25556447.

5) Iranian Annual of National Cancer Registration Report. Tehran: Ministry of Health and Medical Education, Center for Disease Control \& Prevention, Deputy for Noncommunicable Disease, Cancer Office, 2008.

6) Prosner MC, Minsky BD, Ilson DH. Cancer of the Esophagus. In: DeVita VT, Lawrence TS, Rosenberg S, editors. Devita, Hellman, and Rosenberg's Cancer: principles and practice of oncology. 1.10 ed. Philadelphia: Lippincott Williams and Wilkins; 2015.

7) Rustgi AK. Molecular Biology of the Esophagus and Stomach. In: DeVita Jr. VT, Lawrence TS, Rosenberg SA, editors. DeVita, Hellman, and Rosenberg's Cancer: Principles \& Practice of Oncology. 1. 10 ed. Philadelphia: Wolters Kluwer; 2015; 570-3.

8) Woo J, Cohen SA, Grim JE. Targeted therapy in gastroesophageal cancers: past, present and future. Gastroenterol Rep (Oxf). 2015; 3(4): 316-29. doi: 10.1093/gastro/gov052. PMID: 26510453, PMCID: PMC4650980.

9) Posner MC, Minsky BD, Ilson DD. Cancer of the Esophagus. In: DeVita Jr. VT, Lawrence TS, Rosenberg SA, editors. DeVita, Hellman, and Rosenberg's Cancer: Principles \& Practice of Oncology. 1. 10 ed. Philadelphia: Wolters Kluwer; 2015; 574-612.

10) Fuchs CS, Tomasek J, Yong CJ, Dumitru F, Passalacqua R, Goswami C, et al. Ramucirumab monotherapy for previously treated advanced gastric or gastro-oesophageal junction adenocarcinoma (REGARD): an international, randomised, multicentre, placebo-controlled, phase 3 trial. Lancet. 2014; 383(9911): 31-9. doi: 10.1016/S0140-6736(13)61719-5. PMID: 24094768.

11) Coulie PG, Van den Eynde BJ, van der Bruggen $P$, Boon $T$. Tumour antigens recognized by $T$ lymphocytes: at the core of cancer immunotherapy. Nat Rev Cancer. 2014; 14(2): 135-46. doi: 10.1038/nrc3670. PMID: 24457417.

12) Boon T, Cerottini JC, Van den Eynde B, van der Bruggen P, Van Pel A. Tumor antigens recognized by $T$ lymphocytes. Annu Rev Immunol. 1994; 12(1): 337-65. doi: 10.1146/annurev.iy.12.040194.002005. PMID: 8011285.

13) Simpson AJ, Caballero OL, Jungbluth A, Chen YT, Old LJ. Cancer/testis antigens, gametogenesis and cancer. Nat Rev Cancer. 2005; 5(8): 615-25. doi: 10.1038/nrc1669. PMID: 16034368.

14) Chen YT, Hsu M, Lee P, Shin SJ, Mhawech - Fauceglia P, Odunsi K, et al. Cancer/testis antigen CT45: analysis of mRNA and protein expression in human cancer. Int J Cancer. 2009; 124(12): 2893-8. doi: 10.1002/ijc.24296. PMID: 19296537.

15) Caballero OL, Chen YT. Cancer/testis (CT) antigens: potential targets for immunotherapy. Cancer Sci. 2009; 100(11): 2014-21. doi: 10.1111/j.1349-7006.2009.01303.x. PMID: 19719775.

16) Chen YT, Ross DS, Chiu R, Zhou XK, Chen YY, Lee P, et al. Multiple cancer/testis antigens are preferentially expressed in hormone-receptor negative and high-grade breast cancers. PloS one. 2011; 6(3): e17876. doi: 10.1371/journal.pone.0017876P. PMID: 21437249, PMCID: PMC3060908.

17) Dyrskjøt L, Zieger K, Kissow Lildal T, Reinert T, Gruselle O, Coche T, et al. Expression of MAGE-A3, NY-ESO-1, LAGE-1 and PRAME in urothelial carcinoma. Br J Cancer. 2012; 107(1): 116-22. doi: 10.1038/bjc.2012.215. PMID: 22596240, PMCID: PMC3389414.

18) Haier J, Owzcareck M, Guller U, Spagnoli GC, Bürger H, Senninger N, et al. Expression of MAGE-A cancer/testis antigens in esophageal squamous cell carcinomas. Anticancer Res. 2006; 26(3B): 2281-7. PMID: 16821603.

19) Chen YT, Panarelli NC, Piotti KC, Yantiss RK. Cancer-Testis Antigen Expression in Digestive Tract Carcinomas: Frequent Expression in Esophageal Squamous Cell Carcinoma and Its Precursor Lesions. Cancer Immunol Res. 2014; 2(5): 480-6. doi: 10.1158/2326-6066.CIR-13-0124. PMID: 24795360.

20) Liang Z, Sun ZY, Yuan YH, Han Y, Wang Y, Gu J, et al. [The expression of 11 cancer/testis (CT) antigen genes in esophageal carcinoma]. Zhonghua Zhong Liu Za Zhia. 2005; 27(9): 534-7. PMID: 16438850.

21) Bolli M, Schultz - Thater E, Zajac P, Guller U, Feder C, Sanguedolce F, et al. NY - ESO - 1/LAGE - 1 coexpression with MAGE - A cancer/testis antigens: A tissue microarray study. Int J Cancer. 2005; 115(6): 960-6. doi: 10.1002/ijc.20953. PMID: 15751033. 
22) Allred DC, Harvey JM, Berardo M, Clark GM. Prognostic and predictive factors in breast cancer by immunohistochemical analysis. M Mod Pathol. 1998; 11(2): 155-68. PMID: 9504686.

23) Mizukami Y, Kono K, Daigo Y, Takano A, Tsunoda T, Kawaguchi Y, et al. Detection of novel cancer testis antigen - specific T - cell responses in TIL, regional lymph nodes, and PBL in patients with esophageal squamous cell carcinoma. Cancer Sci. 2008; 99(7): 1448-54. doi: 10.1111/j.13497006.2008.00844.x. PMID: 18452554.

24) Kono K, Mizukami Y, Daigo Y, Takano A, Masuda K, Yoshida K, et al. Vaccination with multiple peptides derived from novel cancer - testis antigens can induce specific $\mathrm{T}$ - cell responses and clinical responses in advanced esophageal cancer. Cancer Sci. 2009; 100(8): 1502-9. doi: 10.1111/j.13497006.2009.01200.x. PMID: 19459850.

25) Suda T, Tsunoda T, Daigo Y, Nakamura Y, Tahara H. Identification of human leukocyte antigen - A24 restricted epitope peptides derived from gene products upregulated in lung and esophageal cancers as novel targets for immunotherapy. Cancer Sci. 2007; 98(11): 1803-8. doi: 10.1111/j.1349-7006.2007.00603.x. PMID: 17784873.

26) Domae S, Ono T, Sasaki A. Cancer/testis antigens: A prospective reagent as diagnostic and immunotherapeutic targets for squamous cell carcinoma of the head and neck. Japanese Dental Science Review. 2014; 50(4): 91-9. doi: 10.1016/j.jdsr.2014.06.001.

27) Suzuki Y, Mimura K, Yoshimoto Y, Watanabe M, Ohkubo Y, Izawa S, et al. Immunogenic tumor cell death induced by chemoradiotherapy in patients with esophageal squamous cell carcinoma. Cancer Res. 2012; 72(16): 3967-76. doi: 10.1158/0008-5472.CAN-12-0851. PMID: 22700877.

28) Toh U, Sasada T, Takahashi R, Itoh K, Akagi Y. Tumor Immunotherapy of Esophageal and Gastric Cancers. Cancer Immunology: Springer; 2015; 185-97.

29) Forghanifard MM, Gholamin M, Farshchian M, Moaven O, Memar B, Forghani MN, et al. Cancer-testis gene expression profiling in esophageal squamous cell carcinoma: identification of specific tumor marker and potential targets for immunotherapy. Cancer Biol Ther. 2011; 12(3): 191-7. doi: 10.4161/cbt.12.3.15949. PMID: 21613820.

30) Akcakanat A, Kanda T, Tanabe T, Komukai S, Yajima K, Nakagawa S, et al. Heterogeneous expression of GAGE, NY - ESO - 1, MAGE - A and SSX proteins in esophageal cancer: Implications for immunotherapy. Int J Cancer. 2006; 118(1): 123-8. doi: 10.1002/ijc.21219. PMID: 16003736.

31) Kinugasa S, Tachibana M, Yoshimura H, Dhar DK, Shibakita M, Ohno S, et al. Esophageal resection in elderly esophageal carcinoma patients: improvement in postoperative complications. The Annals of Thoracic Surgery. 2001; 71(2): 414-8. doi: 10.1016/S0003-4975(00)02333-X. PMID: 11235680.

32) Kavalar R, Sarcevic B, Spagnoli GC, Separovic V, Samija M, Terracciano L, et al. Expression of MAGE tumour-associated antigens is inversely correlated with tumour differentiation in invasive ductal breast cancers: an immunohistochemical study. Virchows Arch. 2001; 439(2): 127-31. doi: 10.1007/s004280100421. PMID: 11561752. 